\title{
"Business performance assessment of small and medium-sized enterprises: Evidence from the Czech Republic"
}

\begin{tabular}{|c|c|c|}
\hline AUTHORS & \multicolumn{2}{|l|}{$\begin{array}{l}\text { Vojtech Stehel (iD) } \\
\text { Jakub Horak (iD) } \\
\text { R } \\
\text { Tomas Krulicky (D) }\end{array}$} \\
\hline ARTICLE INFO & \multicolumn{2}{|c|}{$\begin{array}{l}\text { Vojtech Stehel, Jakub Horak and Tomas Krulicky (2021). Business performance } \\
\text { assessment of small and medium-sized enterprises: Evidence from the Czech } \\
\text { Republic. Problems and Perspectives in Management, 19(3), 430-439. } \\
\text { doi:10.21511/ppm.19(3).2021.35 }\end{array}$} \\
\hline DOI & \multicolumn{2}{|c|}{ http://dx.doi.org/10.21511/ppm.19(3).2021.35 } \\
\hline RELEASED ON & \multicolumn{2}{|l|}{ Wednesday, 22 September 2021} \\
\hline RECEIVED ON & \multicolumn{2}{|l|}{ Thursday, 28 January 2021} \\
\hline ACCEPTED ON & \multicolumn{2}{|l|}{ Monday, 13 September 2021} \\
\hline LICENSE & \multicolumn{2}{|c|}{$\begin{array}{l}\text { This work is licensed under a Creative Commons Attribution } 4.0 \text { International } \\
\text { License }\end{array}$} \\
\hline JOURNAL & \multicolumn{2}{|c|}{ "Problems and Perspectives in Management" } \\
\hline ISSN PRINT & \multicolumn{2}{|l|}{$1727-7051$} \\
\hline ISSN ONLINE & \multicolumn{2}{|l|}{$1810-5467$} \\
\hline PUBLISHER & \multicolumn{2}{|c|}{ LLC "Consulting Publishing Company "Business Perspectives" } \\
\hline FOUNDER & \multicolumn{2}{|c|}{ LLC "Consulting Publishing Company "Business Perspectives" } \\
\hline$\sigma^{0}$ & 4 & 三ニ: \\
\hline NUMBER OF REFERENCES & NUMBER OF FIGURES & NUMBER OF TABLES \\
\hline 25 & 8 & 2 \\
\hline
\end{tabular}

(c) The author(s) 2021. This publication is an open access article. 


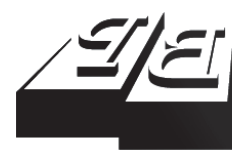

\section{BUSINESS PERSPECTIVES}

(O)

LLC "CPC "Business Perspectives"

Hryhorii Skovoroda lane, 10,

Sumy, 40022, Ukraine

www.businessperspectives.org
Received on: $28^{\text {th }}$ of January, 2020 Accepted on: $13^{\text {th }}$ of September, 2021 Published on: $22^{\text {nd }}$ of September, 2021

(c) Vojtech Stehel, Jakub Horak, Tomas Krulicky, 2021

Vojtech Stehel, Ph.D., Head of the Faculty of Technology, The Institute of Technology and Business in České Budějovice, Czech Republic. (Corresponding author)

Jakub Horak, M.Sc., Deputy Director, Department of Research, Development and Creative Activities, The Institute of Technology and Business in České Budějovice, Czech Republic.

Tomas Krulicky, M.Sc., Head of School of Expertness and Valuation, The Institute of Technology and Business in České Budějovice, Czech Republic.
Vojtech Stehel (Czech Republic), Jakub Horak (Czech Republic),

Tomas Krulicky (Czech Republic)

\section{BUSINESS PERFORMANCE ASSESSMENT OF SMALL AND MEDIUM-SIZED ENTERPRISES: EVIDENCE FROM THE CZECH REPUBLIC}

\begin{abstract}
Business performance assessment is one of the basic tasks of management. Business performance can be assessed using a number of methods. The basic ones include financial analysis, Balanced Scorecard or Economic Value Added (EVA). The paper is focused on SME business performance assessment based on Economic Value Added, calculated using the INFA build-up model. According to this method, companies were divided into four categories. The first category included companies with a positive EVA value. The second category included companies with negative EVA, but with the economic result above the risk-free rate. The third category included companies with a positive economic result above the risk-free rate. The fourth category included companies with a negative economic result. The model did not include companies with negative equity. The input represented 15 predictors based on their financial statements. The data were normalized and all extreme values, likely caused by a data rewriting error, were removed. Company performance is visualized by comparing Principal Component Analysis and Kohonen neural networks. Compared to similar research, the methods are compared using the data that analyzes the performance of companies. Both methods made it possible to visualize the given task. With regard to the purpose of facilitating the interpretation of the results, for the given case, the use of PC seems to be more appropriate.
\end{abstract}

\section{Keywords}

principal component analysis (PCA), Kohonen neural networks (KNN), neural networks, enterprise management

\section{JEL Classification G17, G32, M21}

\section{INTRODUCTION}

When running a business, it is often necessary to make decisions in very complex processes (Synek, 2011). Assessing the influence of individual predictors is often difficult and time-consuming, especially in the case of a dimensional decision problem when individual predictors influence the result (Oo \& Thein, 2019). For business managers, mathematical models are often difficult to understand and interpret. Here, the visualization of data can be very useful for the interpretation of the results supporting the decision-making process (Marakas, 1999). The objective is to compare the use of the PCA method and Kohonen neural networks (Matlabacademy, 2019) for the visualization purposes in the classification of businesses. A comparison of these methods (Brosse et al., 2001) has already been analyzed in technical fields (Blayo \& Demartines, 1991). Newly, these methods are also used to analyze economic factors predicting the performance of small and medium-sized enterprises in the Czech Republic. Thus, the paper is aimed at assessing SMEs' business performance based on Economic Value Added, calculated using the INFA build-up model. 


\section{THEORETICAL BASIS}

\subsection{Business performance assessment}

There are several approaches to assessing business performance. The traditional approach deals with horizontal and vertical financial analysis (Vochozka, 2011), where it is possible to assess a wide range of indicators from activity to Return on Equity (ROE), which is the most frequently used one. ROE is calculated as follows:

$$
R O E=\frac{E A T}{E}
$$

where $E A T$ is earning after $\operatorname{tax}, E$ is equity.

The approach using horizontal and vertical analysis has a number of benefits and shortcomings. The main shortcomings include an independent view of individual indicators that can often be distorted by the character of the business or high degree of risk, which is not considered in the formula.

Another possible approach is Value Based Management (Nývltová \& Marinič, 2010). This method compares the overall benefit of the investment with its costs. The calculation is carried out using the following formula:

$$
R t=((P t+1-P t)+D t+1) / P t,
$$

where $R t$ is the total return to the shareholder; $P t$ +1 is the value (price) of investment at the end of the period (given by the share price and number of shares); $P t$ is the value (price) of investment at the beginning of the period (given by the share price and number of shares); $D t+1$ is dividend yield.

This method is the base of the approaches based on Market value added and Economic value added. Performance can be assessed in terms of economic value added (Neumaierová, 1998), whose results can be used for business management (Neumaierová, 2003). Moreover, EVA results can be used as an input for business valuation (Mařík, 2011), as an assessment of financial health of companies (Vrbka \& Rowland, 2019) or as a motivation system for managers (Kislingerová, 2007).
On the other hand, the performance can be assessed by Balanced Scorecard (Kaplan \& Norton, 1992). Alternative possibilities of business performance assessment can include neural networks and others (Machová \& Vochozka, 2019).

This study also focuses on Economic Value Added, since it is a clearly measurable method that is also suitable for small and medium-sized enterprises.

\subsection{Economic Value Added (EVA)}

EVA is calculated using the build-up model as follows (Neumaierová, 1998). There is an alternative approach based on the CAPM method (Vochozka, 2011); however, it is not suitable for small and medium-sized enterprises.

First of all, cost of equity is calculated:

$$
r_{e}=\frac{W A C C \cdot \frac{C}{A}-(1-t) \cdot \frac{r_{d}}{D} \cdot\left(\frac{C}{A} \cdot \frac{E}{A}\right)}{E / A}
$$

where $A$ represents total assets, $E$ is Equity, $D$ is long-term liabilities, $r_{d}$ is cost of borrowed capital, and WACC - average weighted cost of capital.

The average weighted cost of capital is calculated as follows:

$$
W A C C=r_{f}+r_{L A}+r_{\text {business }}+r_{\text {FinStab }},
$$

where $r_{\text {business }}$ is business risk, $r_{\text {Finstab }}$ is financial stability risk, $r_{f}$ is risk-free rate, and $r_{L A}$ is risk involved in capital structure.

Economic value added is finally calculated as follows:

$$
E V A=\left(R O E-r_{e}\right) \cdot E,
$$

where $R O E$ is return on equity, and $r_{e}$-alternative cost of equity.

\subsection{Principal component analysis}

Principal component analysis is a method that reduces the number of predictions. Generally, the reduction of decision problem to the key components is very important for the management, 

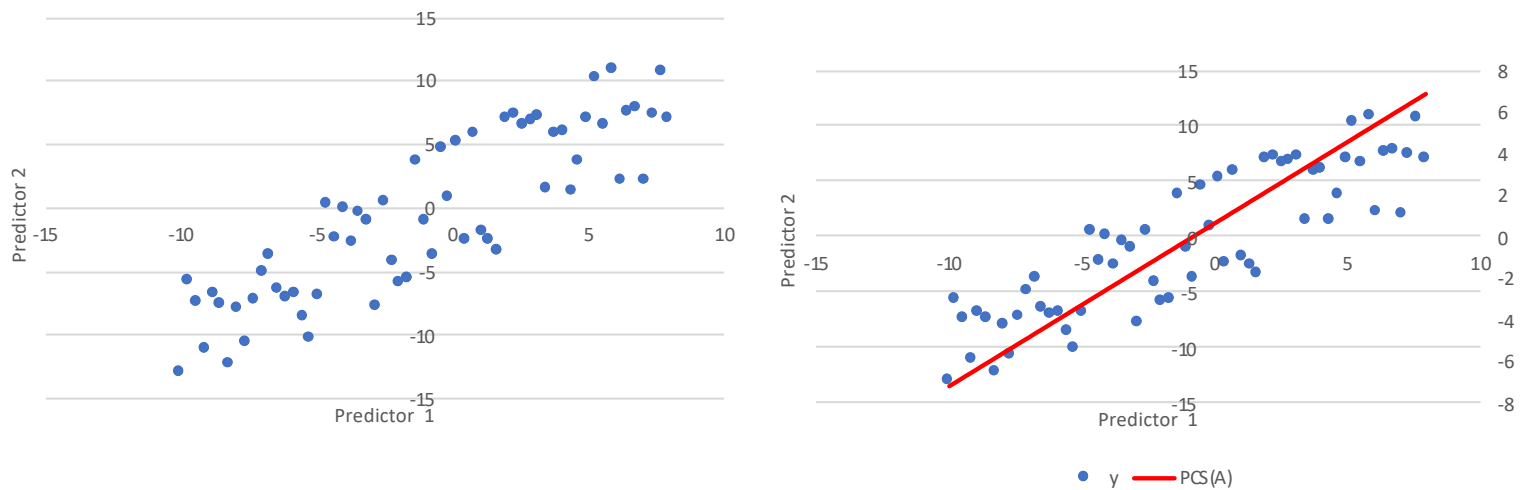

Figure 1. Principle of the PCA method

since it clarifies the decision process and makes the interpretation easier. The reduction is carried out by means of converting the original predictors, which are partly correlated into a new space with a reduced number of predictors (Shaw, 2003) that are independent of each other. Due to this fact, complex methods with reduced data can be applied, and new predictors can be used to visualize the task more easily. The method appeared at the beginning of the 20th century (Pearson, 1901), and was subsequently developed and named (Hotelling, 1933). Its greater use is associated with the development of information technology, where visualization plays a significant role and is not time-consuming in terms of individual partial measurements.

An important feature of this method is that each of the new components is a linear combination of the original predictors. This prevents the loss of the original data. The linear combination of the individual parts of the predictors into a component enables monitoring the variance of the relevant component. The greater the variance, the more important is the component for the prediction. Sorting the individual components by variance allows dividing the components into significant and less significant and determining the percentage importance of the component. Business management thus has the information on the parameter that influences decision making, as well as on the importance of this parameter. In practice, it is not possible to address absolutely all the facts in the micro and macro environment. For this reasons, various systems are used, such as ABC, where management is first and foremost committed to the most important components with the greatest impact on the result, and subsequently to other components.

Figure 1 shows the principle of PCA. On the left side, there is a data set whose location in space is determined by two predictors. On the right side, there is a line that best defined the data in the given space. The slope of the line is determined on the basis of minimizing the distance between the individual dots from the line.

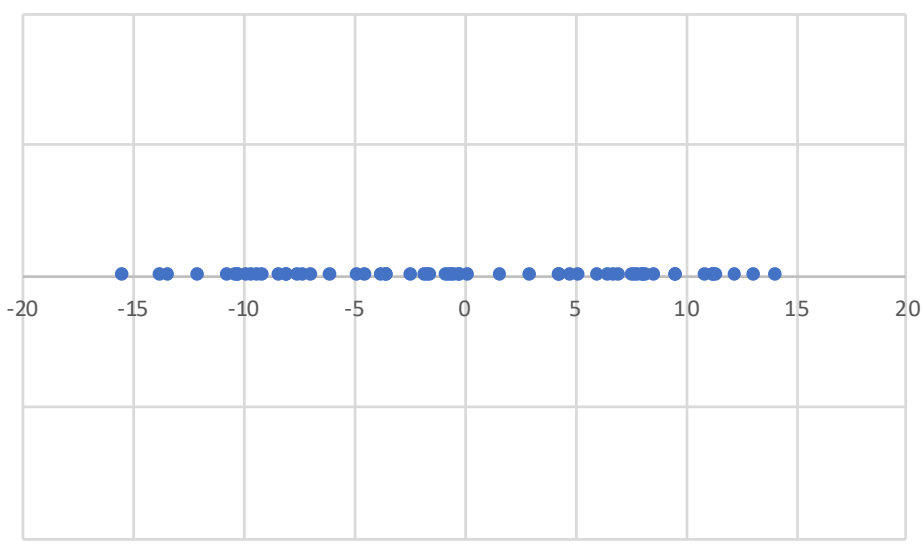

Figure 2. One-dimensional space 


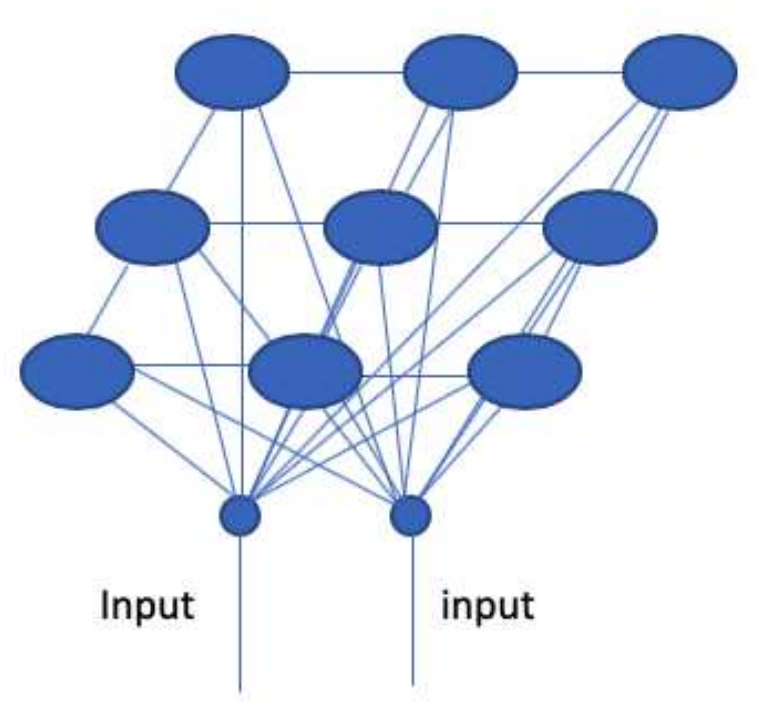

Figure 3. Kohonen network

The line in Figure 1 (the right side) is a new component (dimension) of PCA, which shows the greatest variance for the given task. Due to this, it is possible to redraw the task into a one-dimensional space (Figure 2). This redrawing causes minimal distortion of the data compared to the situation when the data is entered in the $\mathrm{x}$ - or $\mathrm{y}$-axis (in the previous case). Thus, it was possible to reduce the number of variables with a minimum loss of information. The PCA method also allows other dimensions to be calculated and data displayed with nearly zero loss of information.

\subsection{Kohonen networks}

Kohonen networks (Kohonen, 1982) are neural networks that learn without a teacher (Vojáček, 2006). The basic idea consists in the random arrangement of neurons in two-dimensional space (Kohonen, 1989). In the following steps, the individual neurons are moved to represent certain data clusters on the basis of the predictors (Buhmann \& Kuhnel, 1992). Each predictor is connected with an individual neuron. The strength of the connection determines the position of a given neuron (Vondrák, 2000). The principle is shown in Figure 3. Figure 3 shows Kohonen network with nine neurons ( $3 \times 3)$, and two inputs (predictors), which are connected with the individual neurons.

\section{METHODOLOGY AND DATA}

After generation from the Bisnode's Albertina database, the data set contained a total of 42,592 data rows. Each row contained the following information:

1. Identification of a company: name, company identification number, municipality, region, municipality size.

2. Information about a company: NACE, number of employees, code of NACE5A, M_NACE, OKEČ5A, year of financial statement.

3. Financial statements for the given year: balance sheet, profit and loss account, statement of cash flows.

4. Selected indicators of profitability, activity, liquidity, indebtedness, productivity, and others.

Preparation of data (MS EXCEL):

1. Calculation of EBIT (by adding taxes, interests and EAT).

2. Calculation of ROA (EBIT/Assets). 
3. Calculation of ROE (EAT/Equity).

4. Calculation of EVA Equity (according to the Neumaiers methodology - MPO).

5. The data set contained all companies meeting all the following conditions.

6. Company size coding by the number of employees is in Table 1 .

7. NACE 5A codes were changed into sections of CZ-NACE (i.e. only the first letter of the classification).

Table 1. Company size coding

Source: Own processing according to Bisnode's Albertina database.

\begin{tabular}{l|c}
\hline \multicolumn{1}{c|}{ Original value } & Code \\
\hline 0 & 0 \\
\hline $1-5$ & 1 \\
\hline $6-9$ & 2 \\
\hline $10-19$ & 3 \\
\hline $20-24$ & 4 \\
\hline $25-49$ & 5 \\
\hline $50-99$ & 6 \\
\hline $100-199$ & 7 \\
\hline $200-249$ & 8 \\
\hline $250-499$ & 9 \\
\hline
\end{tabular}

The modification reduced the data set from 42,592 rows to 29,611 rows (in Table 2).

Table 2. Number of companies in original and modified data set

Source: Own processing

\begin{tabular}{c|c|c}
\hline Year & Original data set & Modified data set \\
\hline 2013 & 7,976 & 5,705 \\
\hline 2014 & 8,059 & 5,492 \\
\hline 2015 & 8,046 & 5,449 \\
\hline 2016 & 8,803 & 5,982 \\
\hline 2017 & 9,708 & 6,983 \\
\hline In total & 42,592 & 29,611 \\
\hline
\end{tabular}

The resulting data set also contains a complete financial statement with several calculated data stated above. The data can thus be considered predictors (more than 100). For these reasons, the resulting set of companies will be reduced to the main components, and in accordance with the Neumaiers' methodology (Ministry of Trade and Industry, 2019), a category of the companies will be determined following the scheme below.
- Value-generating companies (positive EVA value) $-R O E>r e$.

- Companies with positive profit and negative EVA value, but exceeding the risk-free rate $r f-r e>R O E>r f$.

- Companies with positive profit, where ROE does not achieve the risk-free rate $-r e>r f>$ $R O E>0$.

- Companies with negative profit.

The data will be involved in further analyses. The main predictors are as follows:

- Total assets - CZK thousands.

- $\quad$ Fixed assets - CZK thousands.

- Current assets - CZK thousands.

- Equity-CZK thousands.

- Borrowed capital - CZK thousands.

- Short-term liabilities.

- Personnel costs - CZK thousands.

- Fixed intangible and tangible assets depreciation - CZK thousands.

- Operating result - CZK thousands.

- Interest payable - CZK thousands.

- Financial result - CZK thousands.

- Economic result for accounting period (+/-) CZK thousands.

- Income tax on ordinary and extraordinary activity - CZK thousands.

- Turnover-CZK thousands.

- Company category.

Displaying more than 20,000 companies was complicated because their high number caused the 
creation of continuous color clusters that covered less frequent clusters in groups. For these reasons, the number of companies was reduced to 4,000 . The percentage of individual categories remained the same. The data was normalized for the methods, as otherwise, the methods would provide erroneous results (Abdi \& Williams, 2010). The normalization was carried out using the "normalize" command. Furthermore, extreme values were removed using the "outliers" command.

\section{RESULTS AND DISCUSSION}

In the first phase, the PCA analysis was carried out. With the normalized data set, the following command was executed:

$$
\begin{aligned}
& {[\text { dimension, score, } \sim, \sim, \text { percentage }]=} \\
& =\operatorname{pca}(\text { table }\{:, 6: \text { end }-1\}),
\end{aligned}
$$

where dimension represents new coordinates for PCA space; score - values of individual companies in new space; percentage - importance (variance) of individual components; pca - command for execution of analysis; table - data source, where the individual rows represent the companies and columns are the predictors described in the methodology.

By means of pareto (procenta) command, a new graph was generated (Figure 4). Figure 4 clearly shows that it is possible to obtain about $80 \%$ of the information from the first three components, and more than $70 \%$ from the first two components. The remaining components are thus of relatively negligible importance.

By means of the "biplot" command, it is possible to see how the individual parts participate in a given component. A positive value represents a positive correlation, while a negative value represents a negative correlation. The result is shown in Figure 5. There are only two components. It is clear from the figure that most components are dependent on each other. For example, the economic result (marked as VH in the figure), Tax, and Operating result are positively correlated both for the fist and the second component. On the contrary, interest payable is negatively correlated with the $2^{\text {nd }}$ component and positively correlated with the $1^{\text {st }} \mathrm{com}$ ponent. Similarly, it is possible to interpret other components of the predictors.

Using the "gscatter" command, the position of companies in two-dimensional space can be visualized.

In the next stage, Kohonen neural network with the dimensions of $5 \times 5$ was created. When creating this network, it is possible to see the mutual dependence of the individual predictors. The result can be seen in Figure 7. The more different color for each node, the less dependent the relevant pre-

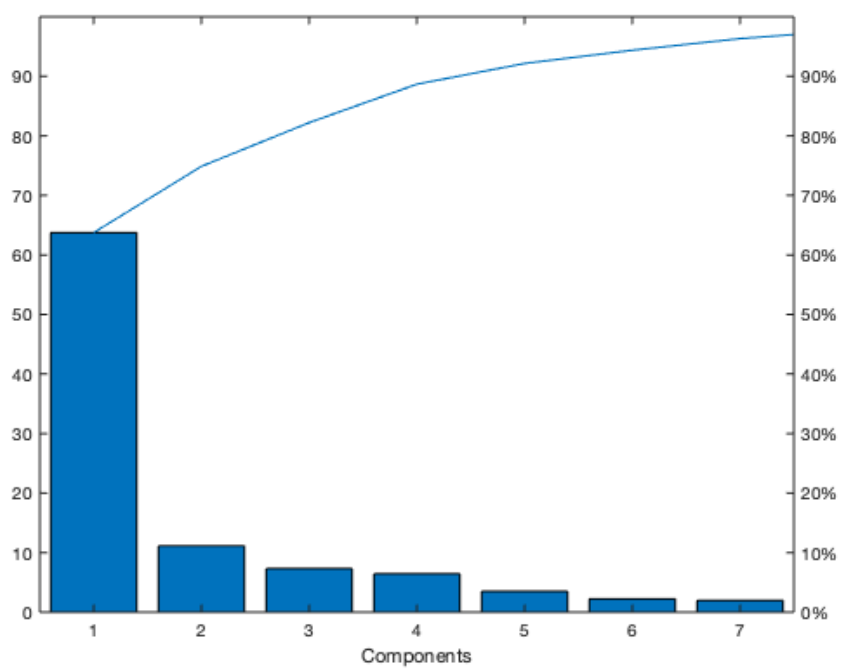

Figure 4. Importance of individual components 


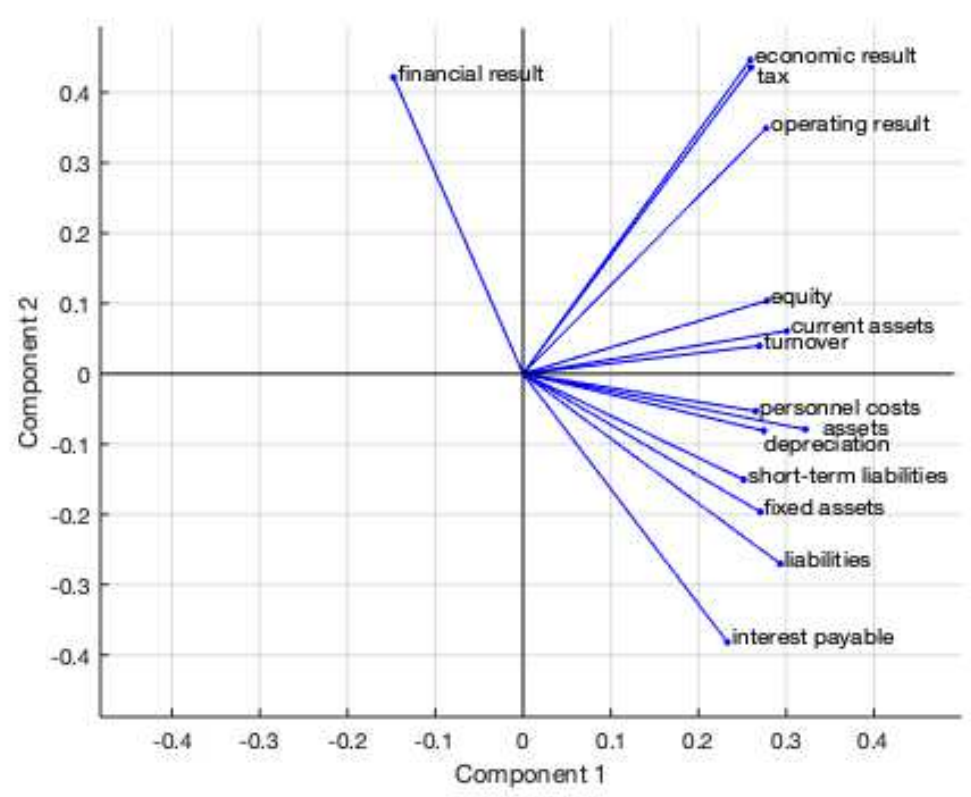

Figure 5. Individual parts involved in a component

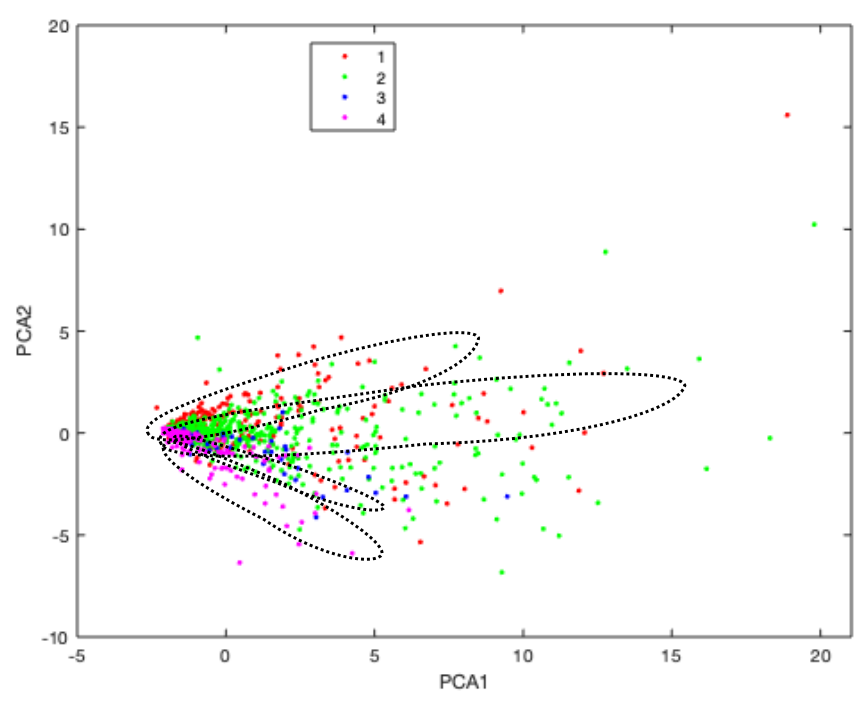

Source: Own processing.

Figure 6. Position of companies in 2-dimensional space

dictors are on each other. For example, predictors 1 and 5 are highly correlated for most neurons. On the contrary, predictor 11 is very little correlated to predictor 12 .

Figure 8 shows the position of the companies and neural networks. On the left side, there are neurons in space by companies. The right side shows a standardized graph showing the percentage of a company category for the given neuron. Particularly the right part of the graph shows that for certain clusters, Kohonen network al- lows creating a representative element (neuron), which will be in the relevant category by company performance.

By means of the "gscatter" command, the position of companies in two-dimensional space can be visualized. Moreover, it is possible to distinguish the individual sets of companies from each other by means of color (see Figure 6). Figure 6 clearly shows 4 groups of companies created in the graph. These groups represent the category of a company according to the INFA methodology. Thus, to 

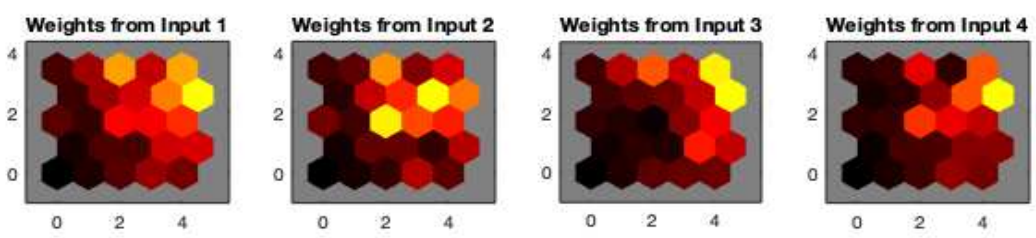

Source: Own processing.
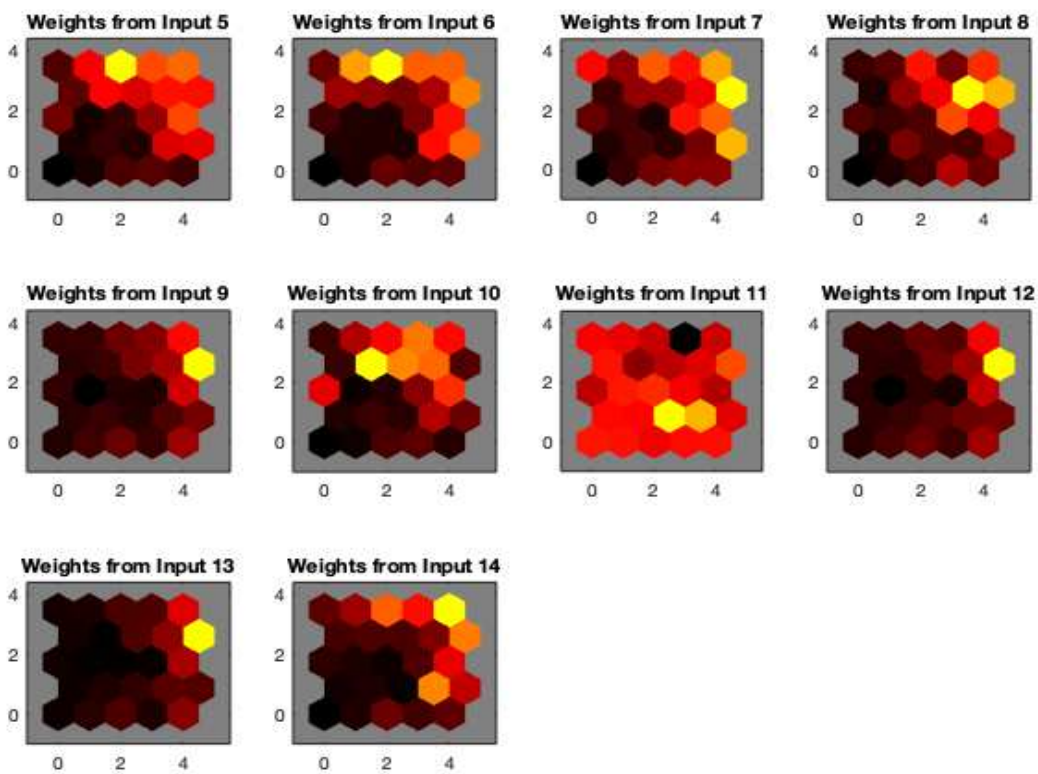

Figure 7. Mutual dependence of the individual predictors
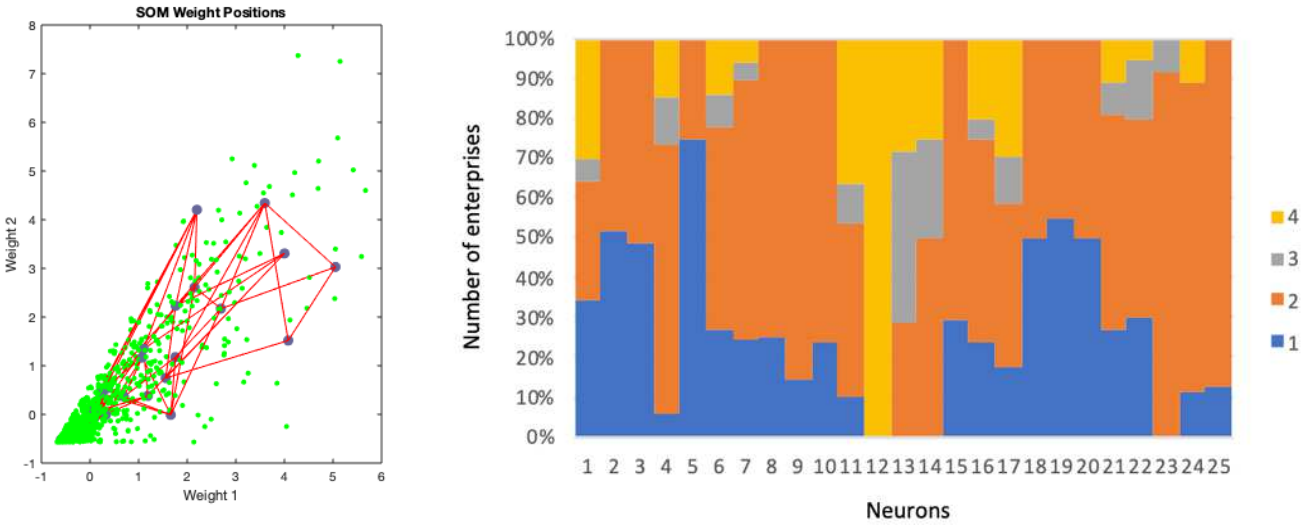

Figure 8. Position of the companies and Kohonen neural networks

a certain extent, the method can categorize the companies according to their performance.

Figure 8 shows the position of companies and neural networks. On the left side, there are neurons in space by companies. The right side shows a standardized graph showing the percentage of a company category for the given neuron. Particularly the right part of the graph shows that for certain clus- ters, Kohonen network allows you to create a representing element (neuron), which will be in the relevant category by company performance.

Both methods allow visualizing business performance, which is important for decision-making systems in business management. Both methods have their advantages and disadvantages. The PCA method eliminates mutually correlated pre- 
dictors and can determine the amount of data lost by the reduction and visualization of only two PCA components. Unlike PCA, there is no loss of information in visualization in the case of Kohonen networks. However, their interpretation is significantly more complicated and thus less applicable for the management in practice in this case.

\section{CONCLUSION}

This study calculated business performance based on Economic Value Added, which is the key information for business management. The calculation method was based on the INFA build-up model. On the basis of this value, performance of these enterprises was visualized using selected items of accounts. Despite its spatial complexity, it was possible to carry out the visualization so that it is useful for the management.

Both methods can be used to visualize company performance. Performance visualization can facilitate the decision-making process in a number of cases (e.g. about the cooperation with a given company, equity investment, etc.). Both methods can provide analytic tools to identify which parameters were used to decide on the classification in a concrete group. With regard to the allowed extent of the paper, these analytic methods were presented and described from the perspective of the most important outcomes.

The objective of the analysis was to simplify the decision-making process by means of visualization. In other words, the visualization was supposed to lead to a segmentation that could be easily interpreted. Given the purpose of the analysis, PCA seems to be a more effective visualization method in this particular case due to easier and more unambiguous identification of the classification of individual companies into sets that express company performance. It is also easier to understand and interpret a company's position in a given space.

The limitation of the study is mainly in the input data, which is based on the obligation of companies in the Czech Republic to publish their financial statements. Nevertheless, the statements are subject to tax optimization, which can be quite easy to implement in the case of small enterprises. In other words, a category 3 or 4 company may, in fact, bring a sufficient return on resources for the owner. However, this return is not shown in the financial statement with respect to the tax deduction. Finally, it shall be mentioned that, despite the legal obligations, not all companies complete financial statements. This is especially true for companies in difficulty. This distorts a number of companies in individual categories.

\section{AUTHOR CONTRIBUTIONS}

Conceptualization: Vojtech Stehel, Jakub Horak.

Data curation: Jakub Horak, Tomas Krulicky.

Formal analysis: Jakub Horak, Tomas Krulicky.

Funding acquisition: Vojtech Stehel.

Investigation: Vojtech Stehel.

Methodology: Vojtech Stehel.

Project administration: Vojtech Stehel.

Resources: Jakub Horak.

Software: Vojtech Stehel, Tomas Krulicky.

Supervision: Vojtech Stehel.

Validation: Vojtech Stehel.

Visualization: Vojtech Stehel.

Writing - original draft: Vojtech Stehel, Jakub Horak.

Writing - review \& editing: Vojtech Stehel. 


\section{ACKNOWLEDGMENT}

This study has been supported by the Technology Agency of the Czech Republic under project No TL01000349.

\section{REFERENCES}

1. Abdi, H., \& Williams, L. J. (2010). Principal component analysis. Wiley Interdisciplinary Reviews: Computational Statistics, 2(4), 433-459. https://doi.org/10.1002/wics.101

2. Blayo, F., \& Demartines, P. (1991). Data analysis: How to compare Kohonen neural networks to other techniques? In A. Prieto (Ed.), Artificial Neural Networks (Lecture Notes in Computer Science) (pp. 469-476). Springer, Berlin, Heidelberg. https://doi.org/10.1007/ BFb0035929

3. Brosse, S., Giraudel, J. L., \& Lek, S. (2001). Utilisation of nonsupervised neural networks and principal component analysis to study fish assemblages. Ecological Modelling, 146(1-3), 159-166. https://doi.org/10.1016/S03043800(01)00303-9

4. Buhmann, J., \& Kuhnel, H. (1992). Unsupervised and supervised data clustering with competitive neural networks. In IJCNN International Joint Conference on Neural Networks (pp. 796-801). https://doi. org/10.1109/ijcnn.1992.227220

5. Hotelling, H. (1933). Analysis of a complex of statistical variables into principal components. Journal of Educational Psychology, 24(6), 417-441. https://doi.org/10.1037/ h0071325

6. Kaplan, R. S., \& Norton, D. P. (1992). The Balanced Scorecard Measures That Drive Performance. Harvard Business Review, 70(1), 71-79. Retrieved from https:// steinbeis-bi.de/images/artikel/ hbr_1992.pdf

7. Kislingerová, E. (2007). Manažerské finance [Managerial Finance] ( $2^{\text {nd }}$ revised and expanded edition). Prague: C. H. Beck.

8. Kohonen, T. (1982). Self-Organized Formation of Topologically Correct Feature Maps. Biological
Cybernetics, 43(1), 59-69. https:// doi.org/10.1007/bf00337288

9. Kohonen, T. (1989). Self-organizing and associative memory ( $3^{\text {rd }} \mathrm{ed}$.). Berlin: Springer-Verlag.

10. Machová, V., \& Vochozka, M. (2019). Using artificial intelligence in analysing and predicting the development of stock prices of a subject company. In S. Ashmarina, \& M. Vochozka (Eds.), Sustainable Growth and Development of Economic Systems: Contradictions in the Era of Digitalization and Globalization (pp. 235-245). Springer, Cham. https://doi.org/10.1007/9783-030-11754-2_18

11. Marakas, G. M. (1999). Decision support systems in the twenty-first century. Upper Saddle River, N.J.: Prentice Hall.

12. Mař́k, M. (2011). Metody oceňování podniku: proces oceněni - základní metody a postupy [Business valuation methods: valuation process - basic methods and procedures] ( $3^{\text {rd }}$ ed.). Prague: Ekopress.

13. Matlabacademy. (2019, December 12). Machine Learning with MATLAB. USA: The MathWorks. Retrieved from https://matlabacademy.mathworks.com

14. Ministry of Industry and Trade. (2019, December, 1). Analytical materials. Retrieved from https:// www.mpo.cz/en/guidepost/analytical-materials-statistics/analyticalmaterials/

15. Neumaierová, I. (1998). Řizení hodnoty [Value Management]. Prague: University of Economics in Prague.

16. Neumaierová, I. (2003). Aplikace rízení hodnoty [Value Management Application]. Prague: University of Economics in Prague.

17. Nývltová, R., \& Marinič, P. (2010). Finanční rízení podniku: moderní metody a trendy [Financial management: modern methods and trend]. Prague: Grada.

18. Oo, M. C. M., \& Thein, T. (2019). An efficient predictive analytics system for high dimensional big data. Journal of King Saud University - Computer and Information Sciences. https://doi.org/10.1016/j. jksuci.2019.09.001

19. Pearson, K. (1901). On Lines and Planes of Closest Fit to Systems of Points in Space. Philosophical Magazine, 2(11), 559-572. https://doi. org/10.1080/14786440109462720

20. Shaw, P. J. A. (2003). Multivariate statistics for the Environmental Sciences. Hodder-Arnold.

21. Synek, M. (2011). Manažerská ekonomika [Managerial economy] ( $5^{\text {th }}$ ed.). Prague: Grada.

22. Vochozka, M. (2011). Metody komplexního hodnocení podniku [Enterprise comprehensive evaluation methods] (1st ed.). Prague: Grada Publishing.

23. Vojáček, A. (2006, December 11). Samoučící se neuronová sit' - SOM, Kohonenovy mapy [Self-learning neural network - SOM, Kohonen maps]. Retrieved from https://www. kiv.zcu.cz/studies/predmety/uir/ NS/Samouc_NN2.pdf

24. Vondrák, I. (2000). Umělá inteligence a neuronové sítě [Artificial intelligence and neural networks] (2 $2^{\text {nd }}$ ed.). Ostrava: Technical University of Ostrava.

25. Vrbka, J., \& Rowland, Z. (2019). Assessing of financial health of companies engaged in mining and extraction using methods of complex evaluation of enterprises. In S. Ashmarina \& M. Vochozka, (Eds.), Sustainable Growth and Development of Economic Systems (pp. 321-333). Springer, Cham. https://doi.org/10.1007/978-3-03011754-2_23 